a localised cavity, into which a posterior ulcer had burst. This at once explained the symptoms, and it is instructive to have discovered the cause of the symptoms and the reason why we were unable to find a rupture.

Remarks by Dr. Renton.

One of the most fatal events that happens is rupture of a gastric or intestinal ulcer, and therefore it is essential that without delay the rupture should if possible be closed. Until recently, 95 per cent. of the cases of ruptured gastric ulcer died, and as the larger proportion of these are women from 14 to 30 years of age, it is most important that the symptoms be promptly recognised. As regards the symptoms, they vary according to whether the ulcer is on the anterior or posterior surface of the stomach. If posterior, there are more organs for the stomach to be attached to, and therefore the symptoms are not so marked. The rupture, however, takes place anteriorly in 84 cases out of 100 . A patient with previous symptoms of indigestion with or without history of hæmorrhagic vomiting who is suddenly seized with acute pain in the upper abdomen with collapse, rapid pulse, temperature $97^{\circ}$, intense pain in the neck, with suffocating feeling, and in addition clear percussion in the liver region, with superficial gurgling over the upper abdomen, may be regarded as having a ruptured gastric or intestinal ulcer. The sooner that abdomen is opened the better, and if you have been wrong, and there is no rupture, you have with proper precaution done no harm. If you delay, you may lose your patient. During the last year, it is encouraging to find that a number of cases of ruptured gastric ulcer have been recorded as successfully operated upon. Their success mainly depended on early recognition of the condition by the practitioner in attendance.

\section{A CASE OF HEMATORRACHIS.}

Bx WILLIAM BAIN, M.D., F.R.C.S.E., M.R.C.P.Lond., Harrogate.

SpINAL meningeal hæmorrhage not due to injury is so exceedingly rare as a cause of death that $I$ think the following case is worth recording.

On the morning of December 22nd, 1894, I received an urgent message to see a housemaid. I was told that the patient, being troubled with constipation, had taken the preceding night two pills which were given her by a friend. She had a good night, got up about 6 A.M., and after dressing went downstairs feeling well. Half an hour afterwards the bowels were moved, and on returning to the kitchen she complained that she felt numb "all over," and had difficulty in walking. After resting some time and not feeling any better she was assisted upstairs.

I saw her about 8 A.M., and found her in a very curious condition. She was propped up in bed complaining of difficulty in breathing, pain in the back of the neck, and loss of motion, and numbness in the upper and lower extremities. Except that she looked pale there was nothing unusual in her expression. She answered my questions intelligently but spoke slowly, with some difficulty, and in a low tone. She told me she was 18, had been anæmic about six months ago, but previous to that, and quite recently, she had been in excellent health. Her catamenia were regular and normal ; the temperature was $98^{\circ}$, the pulse was $5^{2}$ and very weak, and respirations 16 a minute. I gave her a tablespoonful of brandy diluted, which she drank slowly, and in a couple of minutes the pulse was 74. The pupils were normal and reacted to light. She could not move the left arm nor the right leg, but she could move the left leg with an effort and the fingers of the right hand slowly. The knee-jerks were absent ; sensation was distinctly lessened but not abolished. She could feel the prick of a pin in both arms and legs, but slie was slow in perceiving it. I hurriedly examined her chest and abdomen but detected nothing abnormal. While I was examining her she asked me to leave the room as she wished to use the bed pan; but before it could be placed under her there was a very copious watery evacuation of the howels, and immediately after she became collapsed and died in a few minutes, the heart continuing to beat after 7 respiration had ceased. The composition of the pills could not be ascertained. Subsequently her mistress recollected that on the morning previous to her death the girl remarked on entering her bedroom that she felt a peculiar reeling sensation as if she were drunk. Her relatives were not aware of there being any case of hæmophilia in the family, and her fellow servant was certain that the girl had not received any injury. Her medical adviser informed me that she only suffered slightly from anæmia. Her blood had not been examined.

On post-mortem examination there were no signs of violence. The body was well developed and well nourished. The thoracic and abdominal organs were perfectly normal. The brain also was normal ; in fact I have never examined healthier organs. In examining the spinal canal from the back, we first removed the spine and transverse processes of the seventh cervical vertebra and worked upwards. We found nothing abnormal until we came to the third cervical. There we saw a clot between the dura mater and the spinal canal, the larger portion of the clot being on the right side. The dura mater was bloodstained. The clot was comparatively small, and only extended from the second to the third cervical vertebra, the dura mater above the second cervical being normal in appearance, thus showing that the clot was formed in situ. Dr. Simcock assisted me at the postmortem examination.

Spinal meningeal hæmorrhages may occur outside the dura mater or within it. Gowers considers extra-meningeal hæmorrhage the more common, while Osler thinks intrameningeal the more frequent. In the extradural variety the blood comes from the large plexus of veins which lie between the dura mater and the bone.

Apart from injury and very occasionally aneurysm, the causes of this rare condition are not obvious. It is easily understood that it may occur in purpuric states, and in the hæmorrhagic forms of acute specific diseases, although even in these it is very uncommon. It has also been attributed to prolonged muscular exertion.

Regarding the cause in this particular case, I cannot suggest even a far-fetched theory. The question one naturally asks oneself is, Do slight cases of anæmia bear any relation, and, if so, what, to cases of spontaneous hæmorrhage?

The symptoms in this case were indicative of a bæmorrhage above the origin of the phrenic nerves. Evidently there must have been some oozing on or before the morning previous to her death, when she complained of feeling as if she were drunk, and possibly the straining at stool may have caused the larger hæmorrhage which produced the fatal termination.

\section{REMARKS ON THE ETIOLOGY, SYMPTOMS, AND TREATMENT OF LATAB, WITH}

\section{A REPORT OF TWO CASES.}

By JOHN D. GIMLETTE, M.R.C.S., L.R.C.P.LOND , Surgeon-Magistrate, Selensing, Ulu Pahang.

THE functional nervous affection which takes its name from a Malay word latah (nervous or ticklish) is of great interest, owing to its comparative rarity and very obscure pathology. A short residence in the ulu or interior of one of the vastest Malay States has afforded an unusual opportunity for making these notes.

CASE I.-Timah, aged 44. native of Kelantan, midwife, was first seen on April 3 rà, 1897 , at Kuala Lipis, Pahang. The patient, a married woman, has had four children; two died in infancy. She could not tell much about her family history. There is apparently no evidence of latah, either in direct or collateral lines. Besides malarial fever and ordinary parasitic skin diseases - the usual afflictions of her race-she contracted syphilis some years ago. Menstruation is said to have commenced about the age of ro years. It has now ceased. For some time-she could not say exactly how long - she has been latah. For the last two years she has complained of regurgitation of fluids from the mouth through the nose. She is a fairly well nourished woman with a natural expression. The chest is well developed, and the heart and lungs are normal. Pu!se $80, w \cdot a k$. The knee- 